\title{
Editorial
}

\section{Education makes people take their medication: myth or maxim?}

It is a source of frustration to many clinicians: you know what the patient's problem is, you know that effective and safe treatment is available, you've explained the disease and its causative mechanisms, the treatment and its principles, and the importance of taking the controller medication daily, you've prescribed this highly effective therapy and you've approached the patient with respect and patience, yet somehow the patient does not take the medication. When this patient has another exacerbation, you know it could have been prevented by following your advice and taking the medication.

When we, as clinicians, are faced with such a nonadherence scenario, our default mode is to repeat the message that we delivered when we first saw the patient and provided selfmanagement education: we stress, once again, that it is really important that the patient takes their daily controller medication. Apparently, many healthcare professionals believe that such repeated education makes people take their medication. In this editorial, we argue that this is a myth. There is extensive high-quality evidence that education, on its own, does not promote adherence to daily controller medication in patients with a chronic disease [1, 2]. There is also evidence to support an effective alternative approach: healthcare professionals can do a lot to promote adherence in their patients through shared decision making
$[1,3,4]$. The key to promoting adherence through education is not in what message we convey, not in the content of information we provide, but in how we provide it. In this sense, the statement in the title is also a maxim: education can certainly promote adherence, if performed effectively. Therefore, we also review the evidence on the principles of effective patient education which healthcare professionals can use to promote adherence.

In this review, most of the evidence and recommendations that we provide on adherence and adherence-promoting communication strategies comes from paediatric studies and our experience in paediatric care. In this setting, parents are primarily responsible for making the decisions on the treatment of their child's medical condition, and most communication about the patient's adherence to daily controller therapy is conducted between adults, i.e. the healthcare professionals and the child's parents or caregivers. This may help to understand why the principles of adherence and nonadherence, and the communication strategies healthcare providers can employ to promote adherence in their patients, are the same in paediatric and adult care. To improve readability of the remaining text, we use the word "patient" to include the people responsible for the patient's medication taking behaviour, irrespective of the patient's age.

@ERSpublications

Education on its own doesn't make people take their treatment as intended. However, when it follows shared decision making, in which patient and doctor together agree on the best course of therapeutic action, education helps patients take their treatment. http://bit.ly/2G2XswD

Cite as: Driever EM, Brand PLP. Education makes people take their medication: myth or maxim? Breathe 2020; 16 : 190338. 


\section{Nonadherence: the most common cause of uncontrolled chronic disease}

Although the guideline-based daily controller medication prescribed for chronic diseases such as asthma shows clinically relevant beneficial effects in clinical trials and meta-analyses, we regularly encounter patients in whom this treatment does not seem to work as well [5]. In patients with such uncontrolled disease, the guidelines prompt us to step up treatment, increase the dose, add more drugs, or screen for relevant comorbidity affecting disease control. Despite their strong evidence base in cases of true therapy-resistant disease, such interventions are not likely to be effective as long as the major underlying cause of poor disease control remains unaddressed: nonadherence to follow treatment recommendations [6-8].

In 2003, the World Health Organization (WHO) summarised the evidence, available at that time, on the scope and the impact of nonadherence [4]. The WHO described it as a "worldwide problem of striking magnitude", with mean adherence rates in chronic disease of $50 \%$, meaning that the average patient with a chronic disease only takes half of the medication doses prescribed to them. It described the consequences of this poor adherence as "poor health outcomes and increased healthcare costs", and it cited a systematic review concluding that "increasing the effectiveness of adherence interventions may have a far greater impact on the

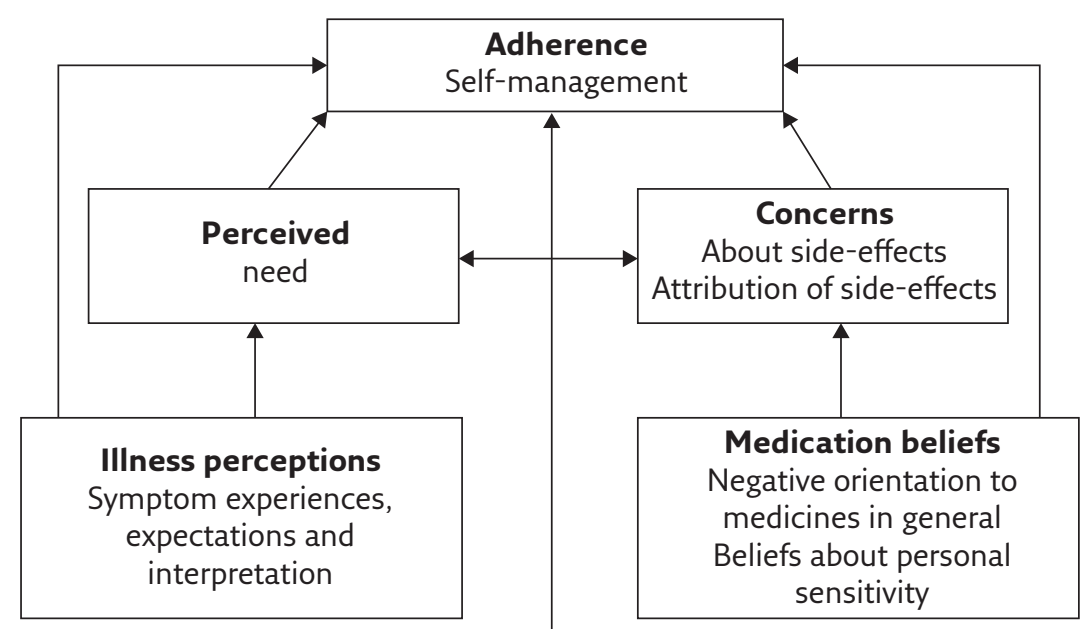

\section{Contextual issues \\ Past experiences \\ Views of others \\ Cultural influences \\ Practical difficulties \\ Self-efficacy \\ Satisfaction}

Figure 1 The common-sense model of medication adherence behaviour. Data from [12, 13]. health of the population than any improvement in specific medical treatments" [9].

Sadly, this situation has not improved much since. Nonadherence in chronic respiratory disease remains common, even in patients with very severe disease. For example, when asthma nurses visited the homes of children referred to a national UK centre because of problematic severe asthma, medication was either absent or out of date in $23 \%$ of cases [10]. The average adherence rate of daily inhaled corticosteroids (ICS) therapy in children with asthma is still around $50 \%[3$, 11], reducing the likelihood of achieving asthma control.

\section{Normal medication adherence behaviour}

The most widely used theoretical model to describe adherence and self-management behaviour in chronic conditions is the so-called common-sense model (figure 1) [12-14]. According to this model, patients develop their own cognitive representations of their illness, including beliefs about causes of the illness, the impact the illness will have on their lives, how long the illness will last, and whether or not it is controllable or curable. Together with the emotional responses to the threat of the illness, these representations are known as "illness perceptions". Illness perceptions are shaped by early experiences with being sick, the response from caregivers and family on sickness, and by accounts of illness in the lay press and on the Internet. Thus, illness perceptions are much more influenced by cultural, social and psychological factors than by "objective" medical severity or demographic characteristics. The patient's illness perceptions strongly determine the patient's perceived need of medication, which is one of the main drivers of adherence [15].

On the other side of the model, driving the perceived concerns about medication, medication beliefs comprise doubts about the necessity of medication to maintain or promote health and concerns about the potential adverse effects of treatment. Both quantitative and qualitative studies show strong associations between these medication beliefs and medication adherence [13, 14]. Patients consciously or unconsciously balance the perceived need and perceived concerns of medication, and the tip of this balance determines the degree of adherence [13]. The word perceived is of key importance - it is the patient's perceived need and concerns of medication that drives their adherence behaviour, not the objective medical need or adverse effects of medication based on evidence and guidelines. This is one of the reasons why simply repeating the objective medical need of taking medication daily is so ineffective: [1, 2] it does not address the most important factors driving adherence behaviour. 


\section{Main forms of nonadherence}

The many factors that affect adherence relate to healthcare systems and healthcare providers (e.g. short consultation time, lack of healthcare providers' knowledge on adherence), social and economic issues (e.g. illiteracy, poverty and lack of support systems), therapy itself (e.g. complexity of treatment and side-effects), patient issues (e.g. self-efficacy and psychosocial stress) and condition-related issues (e.g. severity of symptoms and comorbidity) [4]. Within this complex interplay of factors associated with adherence, three different types of nonadherence can be distinguished (table 1).

Unwitting nonadherence relates to patients who do not understand the rationale or logic of the treatment (e.g. do not know the difference between brown and blue inhalers), mix up different treatments (e.g. use the blue inhaler daily and the brown as needed), or misunderstand dosing regimens (e.g. take medication once every 4 days instead of four times a day). This may be affected by patients' cognitive abilities, language barriers and individual's health literacy.

Unwitting adherence can be addressed by education on the rationale of treatment, e.g. the difference between daily controller therapy and reliever therapy. However, the documented ineffectiveness of such education [1, 2] suggests that unwitting nonadherence, although it does occur occasionally, is not the main cause of nonadherence.

Erratic (or chaotic) nonadherence relates either to the complexity of the treatment itself or to the chaos of the patient's life. Failing to understand a complex treatment schedule could also be classified as a form of unwitting nonadherence, and this should be amenable for targeted education. The chaos of a patient's life, however, is less easily adjustable. In families dealing with serious issues like poverty and debt, psychiatric disease, addiction, violence, unemployment or relationship problems, these issues can take priority over taking medication every day [16, 17]. Repeating or providing education on disease mechanisms and rationale of treatment, or on the importance of taking medication daily, will have little effect on these patients. Helping these patients to successfully self-manage their disease requires tailored support after careful elucidation of factors contributing to nonadherence [16, 17].

Research suggests that deliberate (or intelligent) nonadherence is the most common type of nonadherence, with a strong association of illness perceptions and medication beliefs to adherence rates $[12,13,15]$. Many patients choose to ignore the healthcare professional's advice to take medication daily. Some of them believe that they know more about the best treatment for them than the healthcare provider does [18], others respect the professional's knowledge and skills but are convinced that there are other, personal or social, considerations which take priority over medical knowledge in
Table 1 The differential diagnosis of nonadherence

\begin{tabular}{ll}
\hline Type of nonadherence & Characteristics \\
\hline Unwitting & $\begin{array}{c}\text { Misunderstand dosing regimen, fail to } \\
\text { understand rationale for treatment }\end{array}$ \\
Erratic (or chaotic) & $\begin{array}{c}\text { Difficulty following treatment because of its } \\
\text { complexity or because of chaos of patients' } \\
\text { lives }\end{array}$ \\
Deliberate (or intelligent) & $\begin{array}{c}\text { Deliberately decide that perceived concerns } \\
\text { of medication outweigh its perceived need }\end{array}$
\end{tabular}

Adapted from [4] and [16].

deciding whether daily controller therapy is good for them (or their child). For example, all parents we interviewed about their view on ICS therapy for their child with asthma disliked or even hated the idea of having to give daily medication to their child, and they used strong words like "poison" and "chemical rubbish" to describe these medication [19].

\section{Assessing adherence and its determinants}

Being able to assess adherence reliably is important because it allows the clinician to understand to what degree poor adherence may play a role in a patient with uncontrolled disease. In addition, knowledge of the type of nonadherence in an individual patient is a prerequisite to be able to provide targeted support to improve adherence and, consequently, improve disease control.

The accuracy of different methods to assess adherence varies considerably (table 2). Patient or parent self-report consistently overestimates true adherence, partly because of social desirability bias [3, 20]. The use of anonymous adherence questionnaires may partly overcome this problem, but adherence assessed by validated questionnaires such as the medication adherence report scale still considerably overestimates adherence assessed objectively by electronic methods [22]. Physicians and asthma nurses also overestimate their patients' adherence [3]. Pharmacy refill rates only assess whether the patients have picked up the medication, not whether they have used it [3, 21]. Weighing or using the dose counters on returned inhalers is more accurate, but still open to "dumping" and falsification [3, 21]. Pharmacological techniques (assessing drug levels in blood or urine) can be technically challenging (given the low systemic availability of drugs like ICS), are costly and require repeated blood or urine samples. Because ICS therapy reduces exhaled nitric oxide fraction $\left(F_{\mathrm{eNO}}\right)$ levels, $F_{\text {eNO }}$ has been proposed as a potential ICS adherence marker. However, we found a poor association between $F_{\text {eNO }}$ levels and adherence in children with asthma followed up for 1 year [24]. 
Table 2 Different methods of assessing adherence

\begin{tabular}{lll}
\hline Method & Accuracy & [Ref.] \\
\hline $\begin{array}{l}\text { Self-report } \\
\text { Validated anonymous questionnaire } \\
\begin{array}{l}\text { Physician or asthma nurse } \\
\text { assessment }\end{array}\end{array}$ & $\begin{array}{l}\text { Highly inaccurate } \\
\text { Highly inaccurate }\end{array}$ & {$[11,20,21]$} \\
$\begin{array}{l}\text { Pharmacy refill rate } \\
\text { Returned inhalers: canister weighing } \\
\text { dose counters }\end{array}$ & Fairly accurate & {$[21]$} \\
$\begin{array}{l}\text { Pharmacological methods: blood/ } \\
\text { urine drug levels }\end{array}$ & Fairly accurate & {$[3]$} \\
$\begin{array}{l}\text { Exhaled nitric oxide measurement } \\
\text { Electronic monitoring }\end{array}$ & Inaccurate & {$[24]$} \\
& Highly accurate & {$[3,21,25]$} \\
\hline
\end{tabular}

Because of their high accuracy, electronic monitoring devices are considered to be the gold standard of adherence assessment [3, 26]. These devices record the exact date and time of each actuation of the inhaler device (in asthma and other diseases using inhaled medication), allowing accurate calculation of adherence as a percentage of the prescribed dosages of medication [26]. Adherence rates $>80 \%$ are needed to achieve optimal asthma control [27, 28].

Although electronic adherence monitoring is recommended in research studies and in cohorts of children with problematic severe asthma $[3,11]$, it is too cumbersome and costly to serve as a standard adherence screening tool in the large majority of patients with mild-to-moderate chronic asthma or other respiratory conditions.

None of the adherence assessment methods (table 2) provides the healthcare professional with a reliable tool to distinguish between the three most common types of adherence (table 1). Taking a history remains the most important tool to obtain information about unwitting or erratic nonadherence [16]. Illness and medication beliefs, the main drivers of deliberate nonadherence, can be assessed by validated questionnaires [29, 30]. In the following sections, we will discuss how these can also be explored by talking to patients, and how this conversation can be used to support the patient in achieving optimal adherence.

\section{Shared decision making}

As discussed above, almost all patients have strong illness and medication beliefs which play a major role in determining adherence to daily controller therapy. Most patients will not express such concerns spontaneously, either out of embarrassment or because they do not want to disappoint the healthcare professional who evidently does their best to help them. Whether or not patients are willing to disclose these adherence-hindering perceptions depends on the patient's trust in their physician [31, 32]. Such trust develops gradually, and is determined more strongly by relational and communicational issues than by the physician's medical competence [33].

Taking a medical history through talking to patients and their families has always been a doctor-centred approach, focusing on obtaining the medical information needed to support clinical reasoning and make a diagnosis [34]. This reflects the long domination of the paternalistic decision-making model in medicine [35]. In the past decades, the increasing recognition of the importance of the patient's perspective on their medical problems and the treatment for these problems, with their impact on adherence and other health-related behaviours, has paved the way for another, more collaborative approach to talking to patients and making decisions in medical consultations. This approach has become known as shared decision making [36, 37]. The evidence supporting shared decision making is considerable (box 1). The justification for the shared decision model primarily comes from the ethical perspective of respecting patients' autonomy [37]. Almost all patients expect and prefer to be involved in the decision making process in consultations with a healthcare professional, and prefer to collaborate with their physician [39]. More generally, shared decision making also appeals to the basic human need of being seen, respected and taken seriously [37]. In studies comparing shared decision making with more traditional doctor-centred approaches in medical consultations, shared decision making is associated with patients being more satisfied with the decision making process, the consultation as a whole and the healthcare professional [37, 38]. In addition, they are more satisfied with the decision taken, which increases their likelihood of following through with the actions related to the decision and, hence, with their adherence to the agreed-upon treatment [3, 38]. In shared decisions, patients also tend to go for less invasive and exhaustive treatment options than with paternalistic decision making, which may have an impact on healthcare costs as well [37].

Despite its strong justification and accumulating evidence for its beneficial effects on relevant patient outcomes, shared decision making is applied in clinical practice to a limited extent only [37]. We recently showed that although most physicians preferred shared decision making, they commonly reverted to paternalistic decision making, primarily because they felt the patient was incapable of being meaningfully involved in the decision at hand [40]. Although many physicians thought they already performed shared decision making, they had a limited view of the steps involved in this process, and they hardly ever made clear that a decision had to be made or invited the patient to express their views on what mattered to them in making 
BOX 1 Evidence supporting the use of shared decision making in consultations [33, 37, 38]

\section{Justification}

- Patients prefer humane, personalised care

- The importance of patients' autonomy allowing them to be actively involved in decisions impacting their health

- Patients prefer to collaborate with their physician

- Basic human need to be taken seriously and listened to respectfully

\section{Effects}

- Increased patient satisfaction with decision-making process and with consultation

- Increased satisfaction with decision being taken, less decisional regret

- Patients choose less exhaustive and invasive treatment options

- Increased adherence

the decision [40]. This is in agreement with earlier findings that healthcare providers ask for caregivers' input on the asthma management plan for their children in only $9 \%$ of cases [41].

\section{How can we move from doctor-centred to patient- centred consultations supporting adherence?}

The considerable body of evidence supporting a patient-centred approach, in particular shared decision making, as a means to improve patients' adherence to the proposed therapy is reviewed in detail elsewhere [3, 42-44]. The communicative strategies involved in patient-centred consultations are summarised in box 2 .

The opening of a consultation sets the scene for the atmosphere in the consultation, and the patient's trust in the clinician [45, 46]. Rapport building and trust are essential in improving adherence [32, 48]. Setting a collaborative agenda can be promoted by asking patients and their families what they wish to discuss during the consultation, instead of starting with the ubiquitous question "how are you?" (which hardly ever generates meaningful information) or asking doctor-centred questions related to diagnosis or management, e.g. questions used to assess asthma control [49].

The first step towards successful shared decision making is to inform the patient that a decision has

BOX 2 Communicative strategies healthcare professionals can employ to promote adherence [3, 33, 45, 46, 47]

\section{Start of the consultation}

- Rapport building

- Collaborative agenda setting

- Aligning expectations

\section{Eliciting the patient's perspective}

- Explore illness and medication beliefs respectfully

- Invite patient to share their views and preferences on treatment and outcomes

- Ask for potential barriers in following through with the treatment plan

\section{Show empathy}

- Foster the relationship with patients and their families throughout the consultation

- Remain mindful of own thoughts, feelings and distractions

- Do not prescribe one therapy, but present options with pros and cons

- Acknowledge patient cues with empathic responses

- Provide information only at request or with the patient's permission

\section{End of the consultation}

- Co-create a plan, respecting and supporting patient' preferences as much as possible

- Invite patient and family to ask questions

- Seek explicit agreement on the treatment plan

- Remain flexible to adjust plan according to patient' preferences 
BOX 3 Practical tips to improve adherence in everyday consultations

- Ask patients what they want to discuss in the consultation

- Emphasise that you feel it is important to hear the patient's views and preferences

- Ask patients specifically about their illness and medication beliefs and their barriers to follow treatment recommendations

- Listen attentively to what they have to say, respond respectfully and empathically

- Provide information and education only at request or after obtaining permission

- Propose treatment rather than prescribing it

- Seek explicit agreement with the shared treatment decision

to be made, and that the healthcare professional values the patient's views and preferences as important input in this process [36, 37]. As discussed above, most patients will not volunteer their illness and medication beliefs, but are willing to discuss them if the physician respectfully asks them to express their views and feelings regarding the medication, and explores these with "curious pursuit" [45]. This will generate important information on the potential role of deliberate nonadherence. Similarly, although patients tend to be reluctant in volunteering information about barriers to adherence like poverty, chaotic family routines, or psychiatric illness (factors related to chaotic nonadherence), most are willing to disclose them to an interested and empathic listener [16, 50]. Empathic and attentive listening will foster the relationship and build trust in consultations [33]. Conversely, reprimanding patients for not achieving the desired level of disease control or not taking the medication as prescribed increases patients' anxiety to come to the consultation, decreases trust in the healthcare professional, and reduces the effects of the education being provided [50].

Even if guidelines for the patient's medical problem show a strong preference for a certain therapy (e.g. ICS for persistent asthma), there is always the option of not applying this therapy. In view of the strong resistance patients express against medication in general [19], we have stopped using the word "prescribing" when discussing treatment, preferring to present the treatment as a proposed option that can be chosen or not. In weighing the pros and cons of such proposed treatment, both medical arguments and the patient's personal views and preferences should be taken into account [3, 37]. Providing information in manageable chunks, only at the patient's request, or after obtaining the patient's consent to provide it, helps in enhancing the patient's motivation to listen to and process the education provided [51-53]

Shared creation of an agreed course of action can help to ensure that the treatment proposed aligns with the patient's views and preferences $[45,46]$, and increases the likelihood of the patient following through with the treatment plan. This can be further supported by asking the patient for their explicit agreement with the treatment plan, and with their confidence in being able to follow it [53].

\section{Practical tips to perform shared decision making and improve adherence in consultations}

Although specific training helps in implementing shared decision making in clinical practice [54, 55], the tips presented in box 3 may help to get started in everyday consultations to move towards more patient-centred care through shared decision making consultations and promote adherence.

Studies in paediatric and adult patients with asthma have shown high adherence to daily controller therapy when the approaches presented in boxes 2 and 3 are taken [27, 56, 57]. For example, in our cohort of children with persistent asthma followed up for 1 year, the median adherence rate was $84 \%$ [27], the highest adherence rate ever reported in a study in patients with a chronic disease. We and others also showed that such high adherence was associated with excellent asthma control $[8,28,58]$, confirming the impact of interventions promoting adherence, as predicted by the WHO in 2003 [4].

\section{Conclusions}

"Education makes people take their treatment" is both a myth and a maxim. Although education is needed to allow patients to understand the rationale and logic of treatment, education on its own does not make patients take their treatment as intended. However, there are methods to use education in such a way that it does promote adherence. Patients will be more likely to understand and accept health education when healthcare professionals take a patient-centred approach, encourage the patient to share their views and preferences on the treatment, and use these to come to a shared treatment decision. Studies have shown that shared decision making improves adherence and, consequently, disease control. 


\section{Affiliations}

\section{Ellen M. Driever ${ }^{1}$, Paul L.P. Brand ${ }^{2,3}$}

${ }^{1}$ Dept of Innovation and Science, Isala Hospital, Zwolle, The Netherlands. .2Dept of Medical Education and Faculty Development, Isala Hospital, Zwolle, The Netherlands. . ${ }^{3}$ LEARN network, University of Groningen and University Medical Centre, Groningen, The Netherlands. .

\section{Conflict of interest:}

E.M. Driever has nothing to disclose. P.L.P. Brand has nothing to disclose.

\section{References}

1. Dean AJ, Walters J, Hall A. A systematic review of interventions to enhance medication adherence in children and adolescents with chronic illness. Arch Dis Child 2010; 95: 717-723.

2. Kahana S, Drotar D, Frazier T. Meta-analysis of psychological interventions to promote adherence to treatment in pediatric chronic health conditions. J Pediatr Psychol 2008; 33: 590-611.

3. Klok T, Kaptein AA, Brand PL. Non-adherence in children with asthma reviewed: the need for improvement of asthma care and medical education. Pediatr Allergy Immunol 2015; 26: 197-205.

4. World Health Organization. Adherence to long-term therapies. Geneva, World Health Organization, 2003.

5. Carroll WD, Wildhaber J, Brand PL. Parent misperception of control in childhood/adolescent asthma: the Room to Breathe survey. Eur Respir J 2012; 39: 90-96.

6. de Groot EP, Kreggemeijer WJ, Brand PL. Getting the basics right resolves most cases of uncontrolled and problematic asthma. Acta Paediatr 2015; 104: 916-921.

7. Hedlin G, Bush A, Lodrup CK, et al. Problematic severe asthma in children, not one problem but many: a GA2LEN initiative. Eur Respir J 2010; 36: 196-201.

8. Jentzsch NS, Camargos P, Sarinho ES, et al. Adherence rate to beclomethasone dipropionate and the level of asthma control. Respir Med 2012; 106: 338-343.

9. Haynes RB, McKibbon KA, Kanani R. Systematic review of randomised trials of interventions to assist patients to follow prescriptions for medications. Lancet 1996; 348: 383-386.

10. Bracken $M$, Fleming L, Hall $\mathrm{P}$, et al. The importance of nurse-led home visits in the assessment of children with problematic asthma. Arch Dis Child 2009; 94: 780-784.

11. Morton RW, Everard ML, Elphick HE. Adherence in childhood asthma: the elephant in the room. Arch Dis Child 2014; 99: 949-953.

12. Horne R. Compliance, adherence, and concordance: implications for asthma treatment. Chest 2006; 130: Supp. 1, 65S-72S.

13. Horne R, Chapman SC, Parham R, et al. Understanding patients' adherence-related beliefs about medicines prescribed for long-term conditions: a meta-analytic review of the Necessity-Concerns Framework. PLoS One 2013; 8: e80633.

14. Santer M, Ring N, Yardley L, et al. Treatment nonadherence in pediatric long-term medical conditions: systematic review and synthesis of qualitative studies of caregivers' views. BMC Pediatr 2014; 14: 63.

15. Kaptein AA, Klok T, Moss-Morris R, et al. Illness perceptions: impact on self-management and control in asthma. Curr Opin Allergy Clin Immunol 2010; 10: 194-199.

16. Klok T, Lubbers $S$, Kaptein AA, et al. Every parent tells a story: why non-adherence may persist in children receiving guideline-based comprehensive asthma care. J Asthma 2014; 51: 106-112.

17. Fiese $\mathrm{BH}$, Everhart RS. Medical adherence and childhood chronic illness: family daily management skills and emotional climate as emerging contributors. Curr Opin Pediatr 2006; 18: 551-557.
18. Weinstein AG. The potential of asthma adherence management to enhance asthma guidelines. Ann Allergy Asthma Immunol 2011; 106: 283-291.

19. Klok T, Brand PL, Bomhof-Roordink H, et al. Parental illness perceptions and medication perceptions in childhood asthma, a focus group study. Acta Paediatr 2011; 100: 248-252.

20. Schultz A, Sly PD, Zhang G, et al. Usefulness of parental response to questions about adherence to prescribed inhaled corticosteroids in young children. Arch Dis Child 2012; 97 : 1092-1096.

21. Jentzsch NS, Camargos PA, Colosimo EA, et al. Monitoring adherence to beclomethasone in asthmatic children and adolescents through four different methods. Allergy 2009; 64: 1458-1462.

22. Garcia-Marcos PW, Brand PL, Kaptein AA, et al. Is the MARS questionnaire a reliable measure of medication adherence in childhood asthma? J Asthma 2016; 53: 1085-1089.

23. Gamble J, Stevenson M, McClean E, et al. The prevalence of nonadherence in difficult asthma. Am J Respir Crit Care Med 2009; 180: 817-822.

24. Klok T, Brand PL. Can exhaled nitric oxide fraction predict adherence to inhaled corticosteroids in atopic and nonatopic children with asthma? J Allergy Clin Immunol Pract 2017; 5: 521-522.

25. Jochmann A, Artusio L, Jamalzadeh A, et al. Electronic monitoring of adherence to inhaled corticosteroids: an essential tool in identifying severe asthma in children. Eur RespirJ 2017; 50: 1700910.

26. Ingerski LM, Hente EA, Modi AC, et al. Electronic measurement of medication adherence in pediatric chronic illness: a review of measures. J Pediatr 2011; 159: 528-534.

27. Klok T, Kaptein AA, Duiverman EJ, et al. Long-term adherence to inhaled corticosteroids in children with asthma: observational study. Respir Med 2015; 109: 1114-1119.

28. Klok T, Kaptein AA, Duiverman EJ, et al. It's the adherence, stupid (that determines asthma control in preschool children)! Eur Respir J 2014; 43: 783-791.

29. Horne R, Weinman J, Hankins M. The belief about medicines questionnaire: the development and evaluation of a new method for assessing the cognitive representation of medication. Psychol Health 1999; 14: 1-24.

30. Broadbent E, Petrie KP, Weinman J. The IIIness Perception Questionnaire: brief. J Psychosom Res 2006; 60: 631-637.

31. Riva S, Monti M, lannello $P$, et al. A preliminary mixedmethod investigation of trust and hidden signals in medical consultations. PLoS One 2014; 9: e90941.

32. Young $\mathrm{HN}$, Len-Rios ME, Brown $\mathrm{R}$, et al. How does patient-provider communication influence adherence to asthma medications? Patient Educ Couns 2017; 100: 696-702.

33. Brand PLP, van Dulmen S. Can we trust what parents tell us? A systematic review. Paediatr Respir Rev 2017; 24: 65-71. 
34. Wassmer E, Minnaar G, Aal NA, et al. How do paediatricians communicate with children and parents? Acta Paediatr 2004; 93: 1501-1506.

35. Emanuel EJ, Emanuel LL. Four models of the physicianpatient relationship. JAMA 1992; 267: 2221-2226.

36. Elwyn G, Durand MA, Song J, et al. A three-talk mode for shared decision making: multistage consultation process. BMJ 2017; 359: j4891.

37. Stiggelbout AM, Pieterse AH, De Haes JC. Shared decision making: concepts, evidence, and practice. Patient Educ Couns 2015; 98: 1172-1179.

38. Stacey D, Legare F, Lewis K, et al. Decision aids for people facing health treatment or screening decisions. Cochrane Database Syst Rev 2017; 4: CD001431.

39. Chewning B, Bylund CL, Shah B, et al. Patient preferences for shared decisions: a systematic review. Patient Educ Couns 2012; 86: 9-18.

40. Driever EM, Stiggelbout AM, Brand PLP. Shared decision making: physicians' preferred role, usual role and their perception of its key components. Patient Educ Couns 2020; 103: 77-82.

41. McGrady ME, Ryan JL, Gutierrez-Colina AM, et al. The impact of effective paediatric adherence promotion interventions: systematic review and meta-analysis. Child Care Health Dev 2015; 41: 789-802.

42. Arbuthnott A, Sharpe D. The effect of physicianpatient collaboration on patient adherence in non-psychiatric medicine. Patient Educ Couns 2009; 77: 60-67.

43. Kuntz JL, Safford MM, Singh JA, et al. Patient-centered interventions to improve medication management and adherence: a qualitative review of research findings. Patient Educ Couns 2014; 97: 310-326.

44. Brand PL, Klok T, Kaptein AA. Using communication skills to improve adherence in children with chronic disease: The adherence equation. Paediatr Respir Rev 2013; 14 219-223.

45. Mauksch LB, Dugdale DC, Dodson S, et al. Relationship, communication, and efficiency in the medical encounter: creating a clinical model from a literature review. Arch Intern Med 2008; 168: 1387-1395

46. Matthias MS, Salyers MP, Frankel RM. Re-thinking shared decision-making: context matters. Patient Educ Couns 2013; 91: 176-179.
47. King A, Hoppe RB. "Best practice" for patient-centered communication: a narrative review. J Grad Med Educ 2013; 5 : 385-393.

48. DiMatteo MR, Haskard-Zolnierek KB, Martin LR Improving patient adherence: a three-factor model to guide practice. Health Psychol Rev 2012; 6: 74-91.

49. Brand PL, Stiggelbout AM. Effective follow-up consultations: the importance of patient-centered communication and shared decision making. Paediatr Respir Rev 2013; 14: 224-228.

50. Lawton J, Waugh N, Noyes $\mathrm{K}$, et al. Improving communication and recall of information in paediatric diabetes consultations: a qualitative study of parents' experiences and views. BMC Pediatr 2015; 15: 67.

51. Hargraves I, LeBlanc A, Shah ND, et al. Shared decision making: the need for patient-clinician conversation, not just information. Health Aff(Millwood) 2016; 35: 627-629.

52. Hibbard $\mathrm{JH}$. Patient activation and the use of information to support informed health decisions. Patient Educ Couns 2017; 100: 5-7.

53. Schaefer MR, Kavookjian J. The impact of motivational interviewing on adherence and symptom severity in adolescents and young adults with chronic illness: a systematic review. Patient Educ Couns 2017; 100: 2190-2199.

54. Diouf NT, Menear $M$, Robitaille $H$, et al. Training health professionals in shared decision making: update of an international environmental scan. Patient Educ Couns 2016; 99: 1753-1758.

55. Harman SM, Blankenburg R, Satterfield JM, et al. Promoting shared decision-making behaviors during inpatient rounds: a multimodal educational intervention. Acad Med 2019; 94: 1010-1018

56. Scott L, Morphew T, Bollinger ME, et al. Achieving and maintaining asthma control in inner-city children. J Allergy Clin Immunol 2011; 128: 56-63.

57. Wilson SR, Strub P, Buist AS, et al. Shared treatment decision making improves adherence and outcomes in poorly controlled asthma. Am J Respir Crit Care Med 2010; 181: 566-577.

58. Engelkes M, Janssens HM, de Jongste JC, et al. Medication adherence and the risk of severe asthma exacerbations: a systematic review. Eur Respir J 2015; 45: 396-407. 